\title{
An experimental investigation for macro-textured tool in hot stamping
}

\author{
Kailun Zheng ${ }^{1, a}$, Jianguo Lin $^{1}$, Denis J. Politis ${ }^{1}$, and Trevor A. Dean ${ }^{2}$ \\ ${ }^{1}$ Department of Mechanical Engineering, Imperial College London, Exhibition Road, \\ London SW7 2AZ, UK \\ ${ }^{2}$ School of Mechanical Engineering, University of Birmingham, Edgbaston, Birmingham B15 2TT, \\ UK
}

\begin{abstract}
This paper presents a method of increasing draw-ability of materials in hot stamping processes using forming tools with macro-scale textures on the tool surfaces. Cold and hot stamping processes of a top-hat shape were conducted to evaluate the effects on macro-scale surface textures on the material drawing. Texture directional and texture ratio effects on the draw-ability have been investigated. A more uniform thickness distribution and improved draw-ability was found using the blankholders with surface textures, which is believed to be caused by the lower temperature loss derived from the smaller contact area.
\end{abstract}

\section{Introduction}

The use of formed aluminium alloy sheets has grown in popularity in recent years for both the automotive and aircraft industries due to the beneficial properties of lower density [1]. A recent aluminium sheet hot stamping method, titled "Solution heat treatment, cold die forming and quenching" $\left(\mathrm{HFQ}^{\mathrm{TM}}\right)$ has been described by Foster et al. [2] offering a wide range of benefits over traditional techniques, including even greater material formability with significantly reduced production times. Forming at elevated temperatures requires the thermo-mechanical and tribology properties between the tool and work-piece to be understood and controlled [3]. A feasible approach to reduce the friction coefficient of the tools is to apply surface texturing on the tool surfaces combined with the application of lubricants [4]. Costa \& Hutchings [5, 6] found that the friction coefficient was greatly reduced by applying a surface pattern with grooves perpendicular to the drawing direction using the strip drawing process. These grooves were believed to act as lubricant reservoirs to enhance the lubrication effect. Franzen et al. [7] focused on the material flow during the deep drawing process by selective texturing on the tool machined macroscopic rolling. The use of these surfaces resulted in a significant increase in friction, which allows an additional control of the material flow during sheet drawing operations.

In this paper, the effects of macro-scale tool surface textures on the stamping process of aluminium alloys are described. The effects of various macro-textures on draw-ability were compared for cold and

\footnotetext{
${ }^{\text {a }}$ Corresponding author: KZ313@imperial.ac.uk
}

This is an Open Access article distributed under the terms of the Creative Commons Attribution License 4.0, which permits unrestricted use, distribution, and reproduction in any medium, provided the original work is properly cited. 


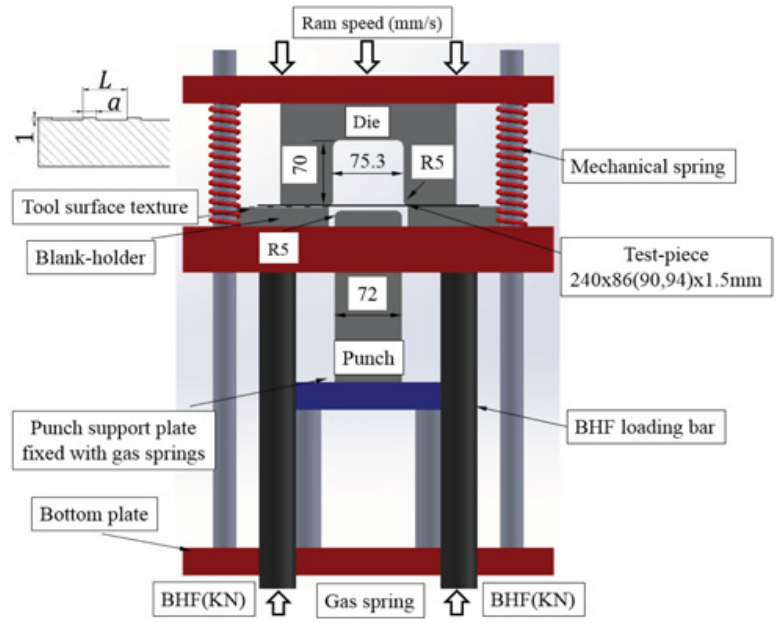

(a) Schematic design of the stamping rig

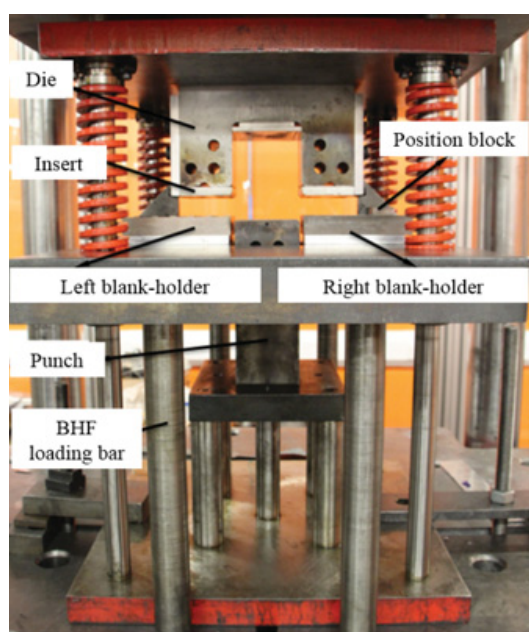

(b) Stamping test set-up

Figure 1. Experimental set-up of the stamping test-rig of a top-hat component.

hot alloy sheet. A flange ratio was defined to compare the material draw-ability. Part shapes formed using tools with macro-textures were compared.

\section{Experimental set-up and test procedure}

\subsection{Experimental set-up}

In order to perform stamping tests of top-hat components, AA6082-T6 aluminium sheets with a thickness of $1.5 \mathrm{~mm}$, were used as the test-piece material. For the cold stamping process, the test-piece was annealed at $415^{\circ} \mathrm{C}$ for one hour and furnace cooled to room temperature in order to obtain the softest temper and hence increase the formability of the material. For the hot stamping process, solution heat treatment (SHT) was performed by heating to $525^{\circ} \mathrm{C} \times 2 \mathrm{mins}$. Rectangular test-pieces with dimensions of $240 \mathrm{~mm}$ long and 86,90 and $94 \mathrm{~mm}$ wide have been used throughout the forming tests corresponding to the texture dimensions on the tools.

Figure 1(a) illustrates the schematic design of the stamping rig. The whole test rig was mounted on a $1 \mathrm{MN}$ ESH hydraulic press with a maximum load $1 \mathrm{MN}$ and maximum ram speed $600 \mathrm{~mm} / \mathrm{s}$. The total stroke was $100 \mathrm{~mm}$. Four blank-holding force (BHF) bars were fixed on a gas cushion system to provide the blank-holding force. During forming, the die moves downwards, compressing the mechanical springs and gas springs until the test-piece is stamped into the die cavity. After forming, the test-piece is compressed with the gas springs to move downwards hence applying a large die closing force to quench the material to room temperature, as required in the HFQ process. Figure 1(b) shows the set-up details of the stamping test. Macro-scale surface textures were machined only on the left blankholder since the material is loaded onto the blank-holders first and retaining a plane right blank-holder provided a means for comparison for the textured surface. To ensure easy and robust clamping over the blankholding area, the die surface was not textured. Also the punch surface was not textured. Two die inserts were fixed on the bottom surface of the die which were replaceable and could be surface treated.

Macro-scale tool textures were machined on the blank-holder surface as shown in Fig. 2(a). A texture ratio was defined as $\mathrm{a} / \mathrm{L}$, where $\mathrm{a} / \mathrm{L}=0$ indicates the knife-edge contact to the test-piece; $\mathrm{a} / \mathrm{L}=1.0$ indicates no texture-full contact to the test-piece. The tool surface textures could be positioned in one of two orientations relative to the material drawing direction during forming. The parallel tool texture 


\section{ICNFT 2015}

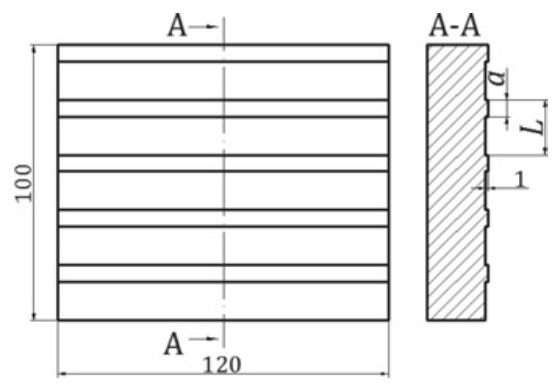

(a) Tool surface texture definition

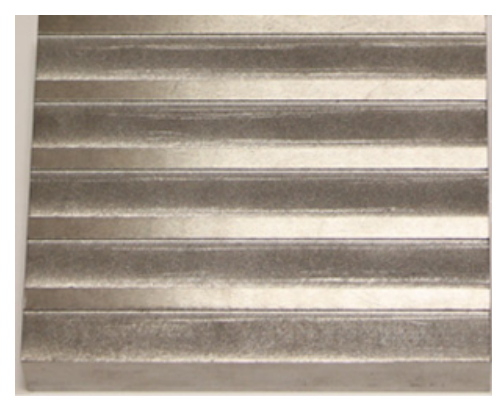

(b) Manufactured tool surface textures

Figure 2. Textured tool surfaces and texture definitions.

Table 1. Experimental conditions and process parameters.

\begin{tabular}{|c|c|c|c|c|c|}
\hline & $\begin{array}{c}\text { Texture } \\
\text { direction }\end{array}$ & $\begin{array}{c}\text { Texture } \\
\text { ratio }\end{array}$ & $\begin{array}{c}\text { BHF } \\
(\mathrm{KN})\end{array}$ & $\begin{array}{c}\text { Forming } \\
\text { speed }(\mathrm{mm} / \mathrm{s})\end{array}$ & $\begin{array}{c}\text { Test-piece } \\
\text { condition }\end{array}$ \\
\hline $\begin{array}{c}\text { Cold } \\
\text { stamping }\end{array}$ & $\begin{array}{c}\text { Perpendicular } \\
\text { Parallel }\end{array}$ & $0.3,0.5,1.0$ & $10,20,30$ & 150 & O condition \\
\hline $\begin{array}{c}\text { Hot } \\
\text { stamping }\end{array}$ & Parallel & $0.3,0.5,1.0$ & $5,10,15$ & 150 & T6 condition \\
\hline
\end{tabular}

is when the angle between the material drawing direction and tool texture is $0^{\circ}$, while an angle of $90^{\circ}$ to this direction is defined as the perpendicular tool texture. Figure 2(b) shows a manufactured tool surfaces. In this paper, texture ratios $0.3,0.5$ and 1.0 were selected in both parallel and perpendicular directions to the material drawing direction.

\subsection{Test procedure}

A series of top-hat shape drawing experiments were conducted in cold stamping and hot stamping conditions with different tool surface textures. Table 1 gives the experimental conditions and process parameters for cold and hot stamping conditions. In the hot stamping processes, once the material was fully solution heat treated, the test-piece was transferred from the furnace to the test-rig within $7 \mathrm{~s}$ with the maximum temperature loss being lower than $50{ }^{\circ} \mathrm{C}$ to minimise the formation of precipitates. After positioning the hot test-piece onto the blankholders, the test-piece was stamped into the die cavity and quenched to room temperature by the cold dies.

\section{Results and discussions}

\subsection{Texture direction effect}

Figure 3 shows cold stamped parts using: (a) full contact (no texture), (b) parallel direction and (c) perpendicular direction blank-holders positioned on the left side of the tool with BHF $10 \mathrm{KN}$ at a forming speed $150 \mathrm{~mm} / \mathrm{s}$. For all these components, the right side blank-holder had no texture. Furthermore, for Fig. 3, all images shown in the red box are taken from the underside of the flange area. In order to reflect the draw-ability using these textured blank-holders on the two sides, a flange ratio $\zeta$ was defined in Eq. (1).

$$
\zeta=L_{\text {left }} / L_{\text {right }} .
$$




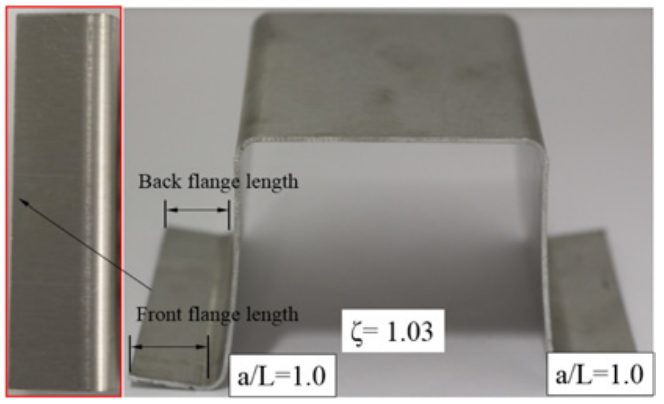

(a) Left: $\mathrm{a} / \mathrm{L}=1.0$ Right: $\mathrm{a} / \mathrm{L}=1.0$

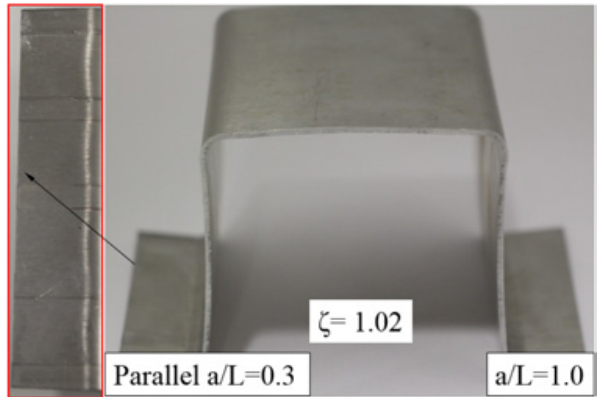

(b) Left: Parallel a/L=0.3 Right: $\mathrm{a} / \mathrm{L}=1.0$

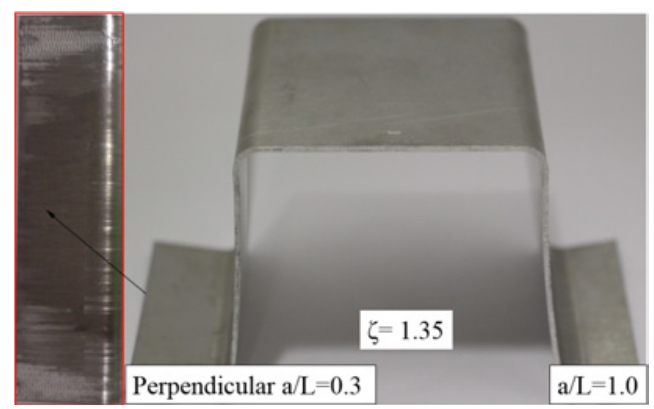

(c) Left: Perpendicular a/L=0.3 Right: $\mathrm{a} / \mathrm{L}=1.0$

Figure 3. Texture direction effect on the flange area for the cold stamped parts using a blank-holding force $10 \mathrm{KN}$ at a forming speed $150 \mathrm{~mm} / \mathrm{s}$.

Here $L_{\text {left }}$ is the flange area length on the left side, $L_{\text {right }}$ the flange area length on the right side. In order to minimise the geometry error, flange lengths were measured both on the front and back sides and a mean value calculated as shown in Fig. 3(a).

The blank surface in Fig. 3(b) exhibits an obvious deformation pattern in the form of a wave believed to be caused by the tool constraint, the flange ratio is 1.02 which is nearly the same as that the Fig. 3(a) which indicates that the parallel tool texture had no constrained effect on material flow. However for the perpendicular tool texture in Fig. 3(c), the flange ratio was 1.35, which indicated the flange length using perpendicular tool texture was greater, the test-piece material was drawn less into the die. From the underside of left side flange area, the blank surface has been scratched which shows that the material was constrained in flowing into the die during the drawing process. It is believed that when a large blank-holding force was applied, the test-piece was elastically deformed [8]. The male tool texture edge may provide a constraint effect on the material flow as the material is elastically deformed. Therefore, the perpendicular direction texture provides a means of preventing material flow into the die.

\subsection{Texture ratio effect}

As the perpendicular tool texture significantly constrains material flow, a series of top-hat shape drawing experiments were performed using parallel tool textures to assess the effect of different texture ratios on material flow during forming.

\subsubsection{Cold stamping}

Figure 4 shows three cold stamped parts formed using tool texture ratios a/L $=0.3,0.5$ and 1.0 on the left side and $\mathrm{a} / \mathrm{L}=1.0$ on the right side. A large $\mathrm{BHF} 30 \mathrm{KN}$ was used to observe the texture ratio effect. 


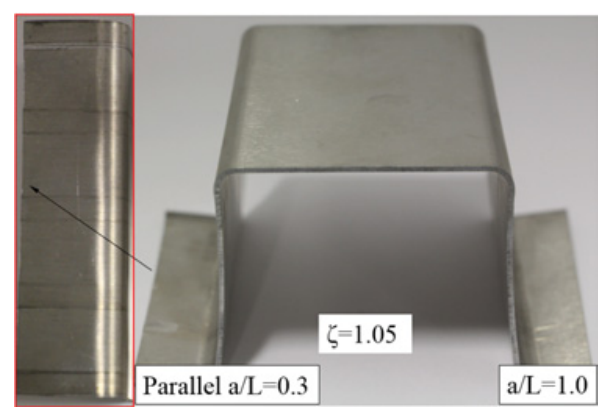

(a) Left: $a / L=0.3$ Right: $a / L=1.0$

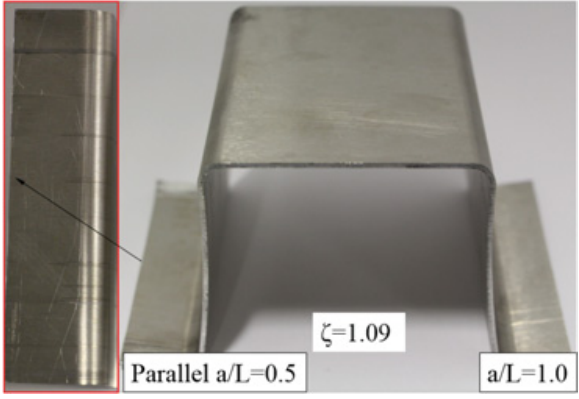

(b) Left: $\mathrm{a} / \mathrm{L}=0.5$ Right: $\mathrm{a} / \mathrm{L}=1.0$

Figure 4. Texture ratio effect on the draw-ability for cold stamping parts with a blank-holding force $30 \mathrm{KN}$ at a forming speed $150 \mathrm{~mm} / \mathrm{s}$.

A constant forming speed of $150 \mathrm{~mm} / \mathrm{s}$ was used for all experiments. The tool texture ratio has an effect on the flange area surface quality, with small texture ratio 0.3 in Fig. 4(a) exhibiting galling marks around the texture feature whereas larger texture ratio 0.5 in Fig. 4(b) exhibit minimal marking. This can be explained by the surface material deformation being greater with decreasing tool texture ratio caused by a greater contact pressure.

In addition, the flange ratios were 1.05 and 1.09 for texture ratio 0.3 and 0.5 , which indicated the parallel texture had no obvious constraint effect on the material drawn in. Material deformation was not significantly constrained when the texture direction is parallel.

Another typical characteristic is the wave outline of the flange edge. The wave flange outline was more obvious with decreasing of tool texture ratio. Such kind of wave was due to the friction force distribution. Material with tool texture contact flowed less because of friction force. The alternate constrained and free flow situation caused by the parallel grooves caused the wave outline of the flange area as shown in Fig. 4. In addition, with the decrease of the texture ratio, the contact area reduces. Hence, comparing a texture ratio of 0.5 , test-piece material using texture ratio 0.3 had less friction force. Due to this, the wave outline became more obvious in comparison with texture ratio 0.5 and 1.0 as shown in Fig. 4.

\subsubsection{Hot stamping}

Figure 5(a) shows the typical top-hat part using the parallel tool texture $\mathrm{a} / \mathrm{L}=0.3$ on the left side and $\mathrm{a} / \mathrm{L}=1.0$ on the right side at a forming speed $150 \mathrm{~mm} / \mathrm{s}$ and BHF $15 \mathrm{KN}$. Compared with the cold stamped part, a clear flange length difference could be found on the two sides. The flange length on the left side is smaller than that on the right side. The possible reasons for this difference is believed to be caused by the tool friction effect and temperature effect of the tool texture. Firstly, less material had friction force using textured blank-holder resulting in a lower overall friction force and therefore material will be drawn in more easily. Secondly, for hot stamping, the top-hat zone material had the highest temperature, compared with the flange area material clamped by the tools firmly. For the right side, at the beginning, the thinning happened at the side wall zone as shown in Fig. 5(a), however, the temperature of this zone was much lower than the top-hat zone, material here became stronger than the top hat zone, so necking occurred at the top hat zone which has shifted to the right side due to the friction effect. Once necking happened, deformation concentrated here as the material was more ductile compared with the flange area, so no more material could be drawn into the die. However, using the textured blank-holder on the left side, the temperature difference between the left side top-hat zone and flange area was small due to the less contact area using textured blank-holder, the lower temperature difference made the left side 


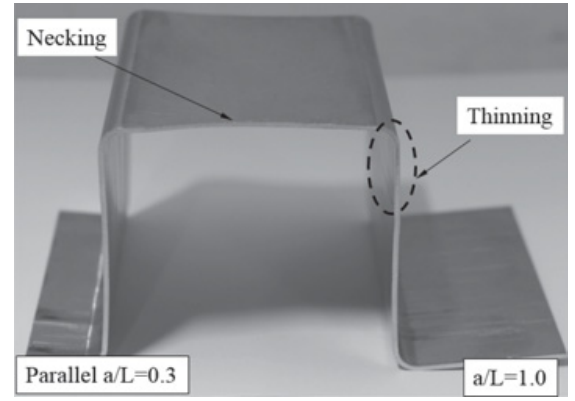

(a) Hot stamped component

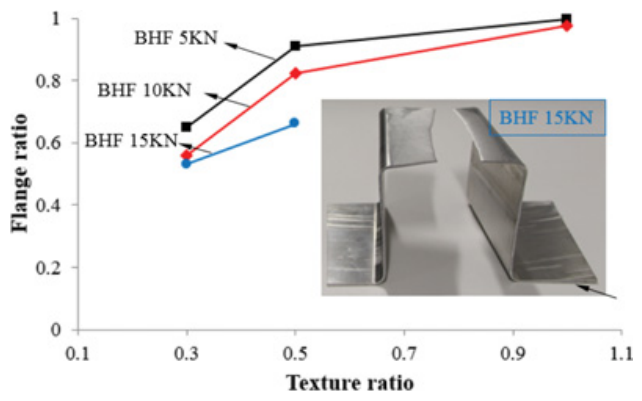

(b) Flange ratio variation

Figure 5. Texture ratio effect on draw-ability of the hot stamped parts using various macro-textures.

top-hat zone exhibit no obvious necking zone, deformation was more uniform and more material could be drawn into the die because of no necking occurring at the top-hat zone.

Figure 5(b) shows the flange ratio variations at different blank-holding forces using textured blankholders with a texture ratio $0.3,0.5$ and 1.0 on the left side, while the right side is fixed with a texture ratio 1.0. The forming speed was $150 \mathrm{~mm} / \mathrm{s}$. Figure 5(b) shows that, the flange ratio increases with increasing texture ratio on the left side at a particular blank-holding force. This might be due to two reasons: firstly, friction force difference on the two sides were less using a higher texture ratio. Secondly, the temperature difference between the flange area and the top-hat area was less on the two sides using a larger texture ratio. The deformation processes were more similar on the two sides which caused the flange ratio increase, when this ratio equals 1.0 means no difference. In addition, using the same texture ratio on the left side tool, the flange ratio increases with the decreasing of the blank-holding force. Using high blank-holding force could provide a high contact pressure, temperature of the material with tool contact may drop quicker than the low blank-holding force case, the temperature differences could be greater and on the two sides material deformation differed, which might cause the decrease of the flange ratio. Taking texture ratio 0.5 as an example, the flange ratio could be decreased from 0.91 to 0.66 , $27.5 \%$ for blank-holding forces $5 \mathrm{KN}$ and $15 \mathrm{KN}$ respectively. For texture ratio 1.0, a crack occurred when the blank-holding force was $15 \mathrm{KN}$ at a forming speed $150 \mathrm{~mm} / \mathrm{s}$.

\section{Conclusions}

The macro-texture orientation of the tool surface has an important effect on the material drawing. Perpendicular texture to material flow constraints the flow compared with a parallel tool texture and non-texture. Texture ratio also affects the material draw-ability especially in the hot stamping processes, a smaller texture ratio could decrease the temperature difference between the top-hat zone and flange zone which contributes more uniform material deformation. The flange difference is believed to be mainly caused by the tool friction effect and the temperature effect on the deformation of the two side material.

\section{References}

[1] L. Wang, M. Strangewood, D. Balint, J. Lin, T.A. Dean., Mater Sci Eng: A, 528(6): 2648-2656 (2011)

[2] A. Foster, T.A. Dean, J. Lin., Patent No. EP 2,324,137, January 16 (2013)

[3] H. Karbasian, A.E. Tekkaya., J Mat Process Tech, 210(15): 2103-2118 (2010) 


\section{ICNFT 2015}

[4] D.Z. Segu, S.G. Choi, J.H. Choi, S.S Kim., Appl Surf Sci, 270: 58-63 (2013)

[5] H.L. Costa, I.M. Hutchings., J Mat Process Tech, 209(3): 1175-1180 (2009)

[6] H.L. Costa, I.M. Hutchings., Tribol Int, 40(8): 1227-1238 (2007)

[7] V. Franzen, J. Witulski, A. Brosius, M. Trompeter, A.E. Tekkaya., International J Mach Tool Manu, 50(11): 969-976 (2010) 